\title{
The unique evolution of the programmed cell death 4 protein in plants
}

\author{
Shijun Cheng ${ }^{1}$, Renyi Liu² and Daniel R Gallie ${ }^{1^{*}}$
}

\begin{abstract}
Background: The programmed cell death 4 (PDCD4) protein is induced in animals during apoptosis and functions to inhibit translation and tumor promoter-induced neoplastic transformation. PDCD4 is composed of two MA3 domains that share similarity with the single MA3 domain present in the eukaryotic translation initiation factor (elF) $4 \mathrm{G}$, which serves as a scaffold protein to assemble several initiation factors needed for the recruitment of the $40 \mathrm{~S}$ ribosomal subunit to an mRNA. Although elF4A is an ATP-dependent RNA helicase that binds the MA3 domain of elF4G to promote translation initiation, binding of elF4A to the MA3 domains of PDCD4 inhibits protein synthesis. Genes encoding PDCD4 are present in many lower eukaryotes and in plants, but PDCD4 in higher plants is unique in that it contains four MA3 domains and has been implicated in ethylene signaling and abiotic stress responses. Here, we examine the evolution of PDCD4 in plants.

Results: In older algal lineages, PDCD4 contains two MA3 domains similar to the homolog in animals. By the appearance of early land plants, however, PDCD4 is composed of four MA3 domains which likely is the result of a duplication of the two MA3 domain form of the protein. Evidence from fresh water algae, from which land plants evolved, suggests that the duplication event occurred prior to the colonization of land. PDCD4 in more recently evolved chlorophytes also contains four MA3 domains but this may have resulted from an independent duplication event. Expansion and divergence of the PDCD4 gene family occurred during land plant evolution with the appearance of a distinct gene member following the evolution of basal angiosperms.
\end{abstract}

Conclusions: The appearance of a unique form of PDCD4 in plants correlates with the appearance of components of the ethylene signaling pathway, suggesting that it may represent the adaptation of an existing protein involved in programmed cell death to one that functions in abiotic stress responses through hormone signaling.

Keywords: MA3 domain, PDCD4, elF4G, elF4A, Translation initiation, Domain duplication, Hormone signaling

\section{Background}

Following transcription and processing of an mRNA, the ribosome is responsible for performing protein synthesis. Although the bacterial $30 \mathrm{~S}$ ribosomal subunit can identify the initiation codon through base-pairing between the 3 '-end of its16 S ribosomal RNA subunit and the Shine-Dalgarno sequence upstream of the initiation codon, the $40 \mathrm{~S}$ ribosomal subunit of the eukaryotic $80 \mathrm{~S}$ ribosome requires several translation initiation factors (eIFs) for its binding to an mRNA and to identify the initiation codon [1-3]. eIF4F, which is composed of eIF4E, eIF4A, and eIF4G, is required to promote $40 \mathrm{~S}$

\footnotetext{
*Correspondence: drgallie@citrus.ucr.edu

'Department of Biochemistry, University of California, Riverside, CA 92521-0129, USA

Full list of author information is available at the end of the article
}

subunit binding to an mRNA. While eIF4E binds to the 5 '-cap structure, eIF4A is an ATP-dependent RNA helicase that hydrolyzes ATP in order to unwind secondary structure present in the $5^{\prime}$-leader of an mRNA that would otherwise inhibit $40 \mathrm{~S}$ subunit scanning during its search for the initiation codon [2]. The helicase activity of eIF4A is enhanced by eIF4B which interacts directly with eIF4A [4-6]. eIF4G is a scaffolding protein that interacts with eIF4E, eIF4A, eIF4B, eIF3 (also required for $40 \mathrm{~S}$ binding to an $\mathrm{mRNA}$ ), and the poly(A) binding protein (PABP) $[2,4,7-9]$. The interaction of eIF4G with eIF4E bound to the $5^{\prime}$-cap and PABP bound to the poly (A) tail circularizes an mRNA and stimulates translation by promoting $40 \mathrm{~S}$ subunit recruitment $[10,11]$.

eIF4A binds to two regions of eIF4G that fold into HEAT (Huntington, Elongation Factor 3, PR65/A, TOR) 
domains, characterized by the presence of antiparallel $\alpha$ helical hairpins known as HEAT repeats [12,13]. One HEAT domain to which eIF4A binds is present in the middle region of eIF4G (HEAT-1/MIF4G, MIG) which is required for translation while the second is $\mathrm{C}$-distal (eIF4G-MA3, HEAT2/MA3) and serves a regulatory function [14-16]. A third, functionally distinct HEAT domain, present in animal eIF4G but absent from plant eIF4G, does not bind eIF4A but does bind Mnk kinase which phosphorylates eIF4E during active translation [17]. eIF4B and PABP also bind to a site within the central region of eIF4G that partially overlaps the HEAT-1/ eIF4G-MIG but they do not bind the HEAT-2/eIF4GMA3 domain [9], demonstrating the functional diversity of the HEAT-1/eIF4G-MIG and HEAT-2/eIF4G-MA3 domains in their interactions with partner proteins. In addition to eIF4G, plants express an eIF4F isoform called eIFiso4F, which is composed of eIFiso4E, eIF4A, and eIFiso4G [18]. The eIF4B and PABP interaction sites overlap with the eIF4A binding site in the HEAT-1/ eIF4G-MIG domain of eIFiso4G more extensively than in eIF4G [19]. As a consequence, eIF4B and PABP compete with eIF4A for binding to the HEAT-1/eIF4G-MIG domain of eIFiso4G in the absence of the HEAT-2/ eIF4G-MA3 domain but not in its presence [19].

In addition to eIF4G, other proteins containing an MA3 domain have been described. The programmed cell death 4 (PDCD4) protein is characterized by the presence of two tandem MA3 domains that fold into a subtype of HEAT domains. The $\mathrm{N}$ - and C-terminal MA3 domains of human PDCD4 contain four and three helical hairpins, respectively, while eIF4G-MA3 contains five helical hairpins [20]. From a basal level, PDCD4 expression is induced upon programmed cell death in several cell types in mice, including lymphoid and neuronal cells [21]. Overexpressing PDCD4 was unable to induce programmed cell death, suggesting no casual relationship between PDCD4 and apoptosis [21]. Increasing PDCD4 expression, however, was sufficient to inhibit tumor promoter-induced neoplastic transformation while reducing PDCD4 expression resulted in a transformation-sensitive phenotype and the promotion of tumor invasion [22-24]. Animal PDCD4 binds eIF4A which inhibits the latter from binding to eIF4G-MA3 [25-27]. PDCD4 inhibits eIF4A RNA binding and helicase activity and inhibits translation in vivo [20,26,28]. PDCD4 binding to eIF4A also disrupts the ATP-binding site and prevents its conformational transition from a nonproductive open state to a productive closed state [28]. PDCD4 binding to eIF4A is required for its ability to inhibit translation and transformation as disruption of eIF4A binding to PDCD4 abolishes its effect on both [26]. The PDCD4 C-terminal MA3 domain contacts the $\mathrm{N}$-terminal domain of eIF4A using structural features conserved with eIF4G-
MA3 thereby preventing the interaction between eIF4A and eIF4G-MA3 and inhibiting translation initiation [29,30]. The two MA3 domains of PDCD4 have similar secondary and tertiary structures and either can compete with eIF4A in binding eIF4G-MA3 [20]. Although both MA3 domains of PDCD4 are structurally similar as are their eIF4A-binding surfaces, the two domains function synergistically to bind eIF4A, resulting in a more stable complex with eIF4A [20]. A single PDCD4 MA3 domain is sufficient to inhibit translation but both domains are required to compete effectively with eIF4G-MA3 for binding to eIF4A [28]. PDCD4 also binds eIF4G-MIG without affecting eIF4A binding as they bind to diametrically opposite sides of eIF4A [28]. Binding of PDCD4 to eIF4G-MIG, however, may anchor the binding of eIF4A to eIF4G-MIG thereby preventing its cycling through eIF4G as part of its function during translation initiation [26].

PDCD4 homologs are present in lower eukaryotes and plants although no PDCD4 homolog has been reported in yeast. PDCD4 proteins in higher plants are unique in that they contain four tandem MA3 domains. Higher plants also appear to lack a two MA3 domain PDCD4 homolog. One such four MA3 domain PDCD4 protein (ECIP1) was reported to bind Arabidopsis thaliana ethylene receptors, ETR2 and EIN4, as well as EIN2, a downstream component of the ethylene signaling pathway required for the induction of ethylene responses [31]. Loss of ECIP1 expression resulted in increased ethylene sensitivity and tolerance to salt [31]. Thus, like the HEAT-2/ eIF4G-MA3 domain of eIF4G and eIFiso4G, the MA3 domains of ECIP1 are involved in protein-protein interactions. When the PDCD4 homolog containing four MA3 domains first appeared during plant evolution has not been examined. In this study, we have examined the evolution of plant PDCD4-like proteins from a two MA3 domain form in prasinophytes to the appearance of a four MA3 domain form in charophytes and land plants and the likely independent appearance of a four MA3 domain form in Chlamydomonadales. We also examine the expansion and divergence of the PDCD4-like gene family during plant evolution and identify how one distinct gene family member appeared following the evolution of basal angiosperms. How the expansion and divergence of the plant PDCD4 gene family might relate to their function as regulators of ethylene responses is also discussed.

\section{Results}

MA3-domains are present in multiple proteins in plants eIF4G contains a single MA3 domain which in plants, is present at the C-terminus as plant eIF4G lacks the HEAT-3/Mnk-binding domain found in animal eIF4G (Figure 1). Plants express two eIF4G isoforms known as eIF4G and eIFiso4G [18]. Although eIFiso4G 


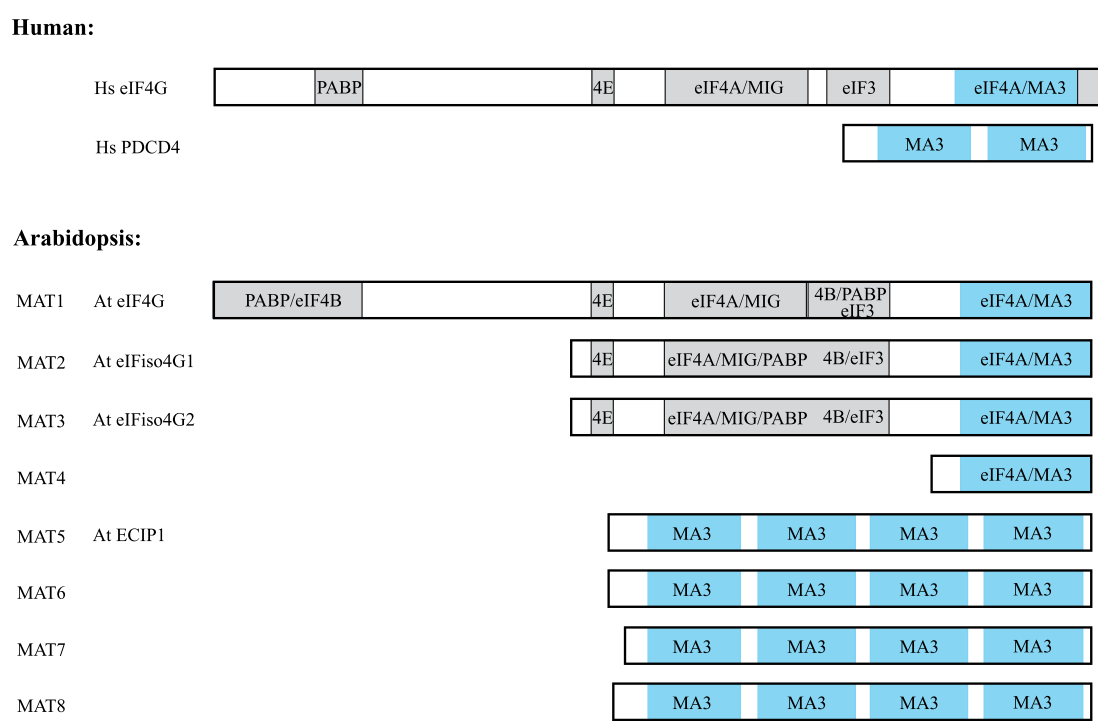

Figure 1 Domain organization of MA3 domain-containing proteins in Homo sapiens and Arabidopsis thaliana. The domain organization of elF4G and PDCD4 proteins is shown for $\mathrm{H}$. sapiens $(\mathrm{Hs})$ and $\mathrm{A}$. thaliana (At). For elF4G, the interaction domains for the translation initiation factors elF4E, elF4A, elF4B, elF3, as well as the poly(A)-binding protein (PABP) and Mnk kinase are shown. The MA3 domains are shown in blue for elF4G and for the animal and plant PDCD4 proteins. MAT5-8 comprise the PDCD4 gene family in A. thaliana. elF4G (MAT1, At3g60240), elFiso4G1 (MAT2, At5g57870), elFiso4G2 (MAT3, At2g24050), MAT4 (At4g30680), MAT5 (At4g24800), MAT6 (At5g63190), MAT7 (At3g48390), MAT8 (At1g22730).

is substantially smaller than eIF4G, this is largely accounted for by a shorter $\mathrm{N}$-terminal region [32]. Consequently, eIF4G and eIFiso4G both contain a Cterminal MA3 domain. In Arabidopsis, eIF4G is encoded by a single gene (i.e., At3g60240) whereas eIFiso4G is encoded by two genes, eIFiso4G1 and eIFiso4G2 (i.e., At5g57870 and At2g24050, respectively) [33]. Another gene (At4g30680) encodes a protein composed largely of a MA3 domain that exhibits similarity to the MA3 domains of eIFiso4G1 and eIFiso4G2 (Figure 1).

In addition to eIF4G, animals express PDCD4, which contains two tandem MA3 domains [21]. A search of higher plants for a similar protein containing two tandem MA3 domains failed to identify a plant homolog. However, a search for other MAT (i.e., MA three) proteins identified four genes, i.e., MAT5 through MAT8, that encode proteins containing four tandem MA3 domains (Figure 1). MAT5 was previously described as ECIP1 which is involved in ethylene signaling and stress tolerance in Arabidopsis thaliana [31]. These authors concluded that three such genes were present in the $A$. thaliana genome but the $A$. thaliana gene family actually contains four members: MAT5 (At4g24800), MAT6 (At5g63190), MAT7 (At3g48390), and MAT8 (At1g22730). Comparison of the MA3 domains from MAT5-8 with eIF4G and eIFiso4G revealed conservation of several residues among all MA3 domains but only four residues were invariant in all MA3 domain proteins (Additional file 1). In addition to the invariant residues, the
MA3 domains of MAT5-8 exhibited conservation at positions that were, in several instances, distinct from residues conserved among eIF4G and eIFiso4G proteins (Additional file 1), suggesting divergence of MA3 domains in MAT5-8 from those in eIF4G and eIFiso4G. Comparison of the MA3 domains of MAT5-8 suggests that MA3 domains 1 and 3 are distinct from MA3 domains 2 and 4, suggesting duplication of an ancestral two MA3 domain protein. That no gene encoding a two MA3 domain homolog is present in higher plants supports the possibility of duplication. Sequence analysis of the individual MA3 domains of MAT5-8 supported this notion as MA3 domains 1 and 3 are more related to one another as are MA3 domains 2 and 4 (Figure 2). Each MA3 domain from MAT8 was the most divergent from the corresponding MA3 domain of MAT5, MAT6, and MAT7, suggesting that the PDCD4 gene family expanded during plant evolution and diverged into a MAT8 subgroup and a MAT5/6/7 subgroup (see below).

The four MA3 domain PDCD4 protein is unique to plants PDCD4 homologs are present throughout angiosperm species and the proteins exhibit considerable conservation both in domain organization and primary sequence (Figure 3). All higher plant PDCD4 proteins contain four tandem MA3 domains in which MA3 domains 1 and 2 and MA3 domains 3 and 4 are separated by just over 50 residues whereas MA3 domains 1-2 are separated from MA3 domains 3-4 by just over half that length. The Nterminus of plant PDCD4 proteins is highly variable in 


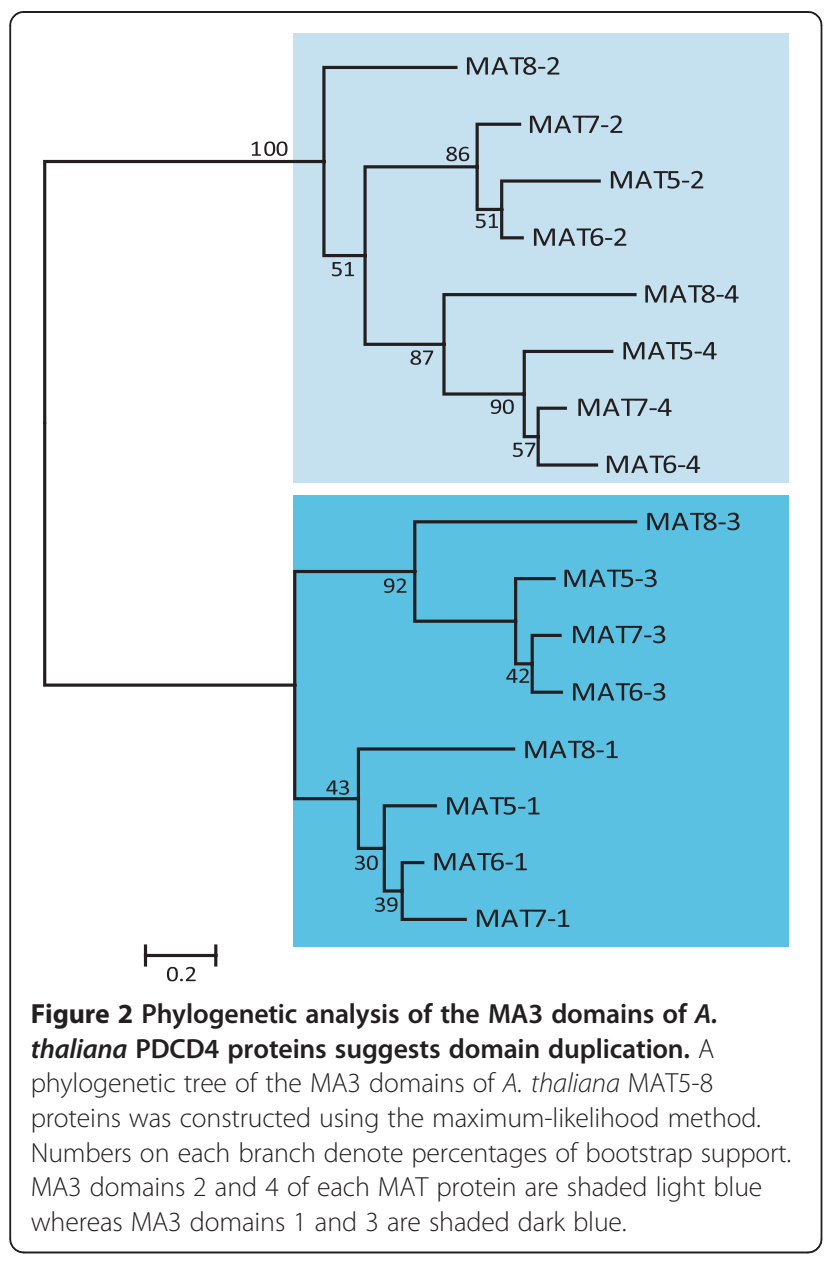

length and sequence with no conservation across angiosperms (Figure 3). Four MA3 domain PDCD4 homologs are present in the bryophyte Physcomitrella patens and in the lycophyte Selaginella moellendorffii (Figure 3), demonstrating that the four MA3 domain form of the protein had appeared prior to the evolution of seed plants. A PDCD4 homolog is also present in the gymnosperm species Picea abies which is conserved with other plant PCDC4 homologs (Figure 3). A partial Pinus taeda cDNA [GenBank: DT628261] exhibited high similarity to MA3 domains 3 through 4 of higher plants (data not shown) suggesting that this gymnosperm species also expresses a four MA3 domain PDCD4 homolog. In contrast, only PDCD4 homologs containing two MA3 domains were found in extensive database searches of animal and lower, non-plant eukaryotic species, indicating that the four MA3 domain PDCD4 homolog is unique to plants.

\section{The four MA3 domain PDCD4 protein arose during algal evolution}

PDCD4 in animals and many lower eukaryotes, including several algal species, contains two MA3 domains while the PDCD4 homolog in other algal species and land plants contains four MA3 domains. This raises the question of when duplication of the two MA3 domain protein into a four MA3 domain protein may have occurred. Examination of the available genome sequences for algae and algal relatives revealed the presence of four MA3 domain PDCD4 homologs in more recently evolved green algae such as Chlamydomonas reinhardtii and Volvox carteri representing the Chlamydomonadales but only two MA3 domain PDCD4 homologs in algal species of the Mamiellales such as Micromonas and Ostreococcus (Additional file 2). Only two MA3 domain PDCD4 homologs were observed in heterokonts such as the brown alga Ectocarpus siliculosus and in algal relatives such as Aureococcus anophagefferens, Phaeodactylum tricornutum, Thalassiisira pseudoonana, Phytophthora species, and Albugo laibachii (Additional file 2).

Phylogenetic analysis of MA3 domains 1-2 and MA3 domains 3-4 of $C$. reinhardtii and V. carteri PDCD4 with the two MA3 domain PDCD4 homologs from other algae and algal relatives revealed that $C$. reinhardtii and $V$. carteri MA3 domains 1-2 were more similar to the two MA3 domain PDCD4 homologs of prasinophytes or heterokonts than were MA3 domains 3-4 (Additional file 3). MA3 domains $1-2$ and MA3 domain 3 of a Chlorella variabilis partial PDCD4 protein sequence also clustered with the respective MA3 domains of $C$. reinhardtii and $V$. carteri PDCD4 (Additional file 3). These data suggest that the four MA3 domain PDCD4 homolog in more recently evolved chlorophytes arose from the duplication of a more ancestral, two MA3 domain protein and that, following duplication, MA3 domains 3-4 diverged to a greater extent than did MA3 domains 1-2.

If the four MA3 domain PDCD4 homolog of $C$. reinhardtii and $V$. carteri arose from the duplication of a two MA3 domain progenitor, any intron present in the gene encoding the progenitor might also have been duplicated during the generation of the four MA3 domain form of the protein. The $C$. reinhardtii and V. carteri PDCD4 genes contain numerous introns some of which are shared between the two. To determine if any may have predated the duplication, the genomic sequence representing MA3 domains 1 to 2 was compared to MA3 domains 3 to 4 of the PDCD4 homologs for both algal species (Figure 4). One intron present in MA3 domain 1 of $C$. reinhardtii and $V$. carteri PDCD4 is present in precisely the corresponding location in the MA3 domain 3 of the same protein (see asterisk, Figure 4), suggesting that it was present in the ancestor of $C$. reinhardtii and $V$. carteri that contained a two MA3 domain PDCD4 progenitor gene that underwent duplication and resulted in a copy of the intron at the same location in MA3 domains 1 and 3. An intron just Cterminal to MA3 domains 1 and 3 and another in MA3 


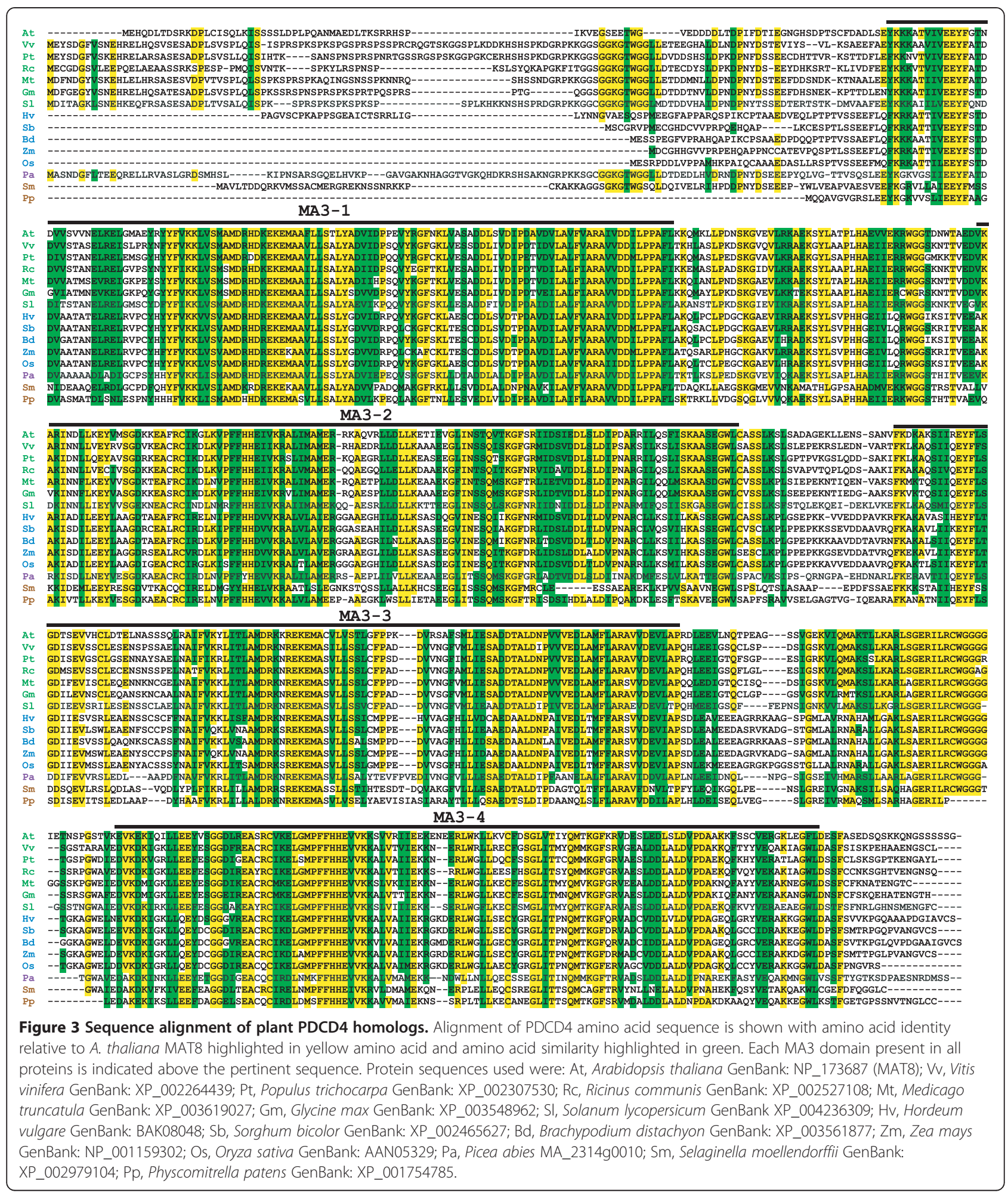

domains 2 and 4 are in near-identical positions but it is not possible to conclude that these predated the duplication event. Nevertheless, the identical position of an intron in MA3 domains 1 and 3 of $C$. reinhardtii and $V$. carteri PDCD4 supports the notion that the four
MA3 domain form of their protein arose through duplication of a two MA3 domain PDCD4 progenitor during their evolution.

As land plants did not evolve from Chlamydomonadales but rather from charophytes (i.e., fresh water algae), the 


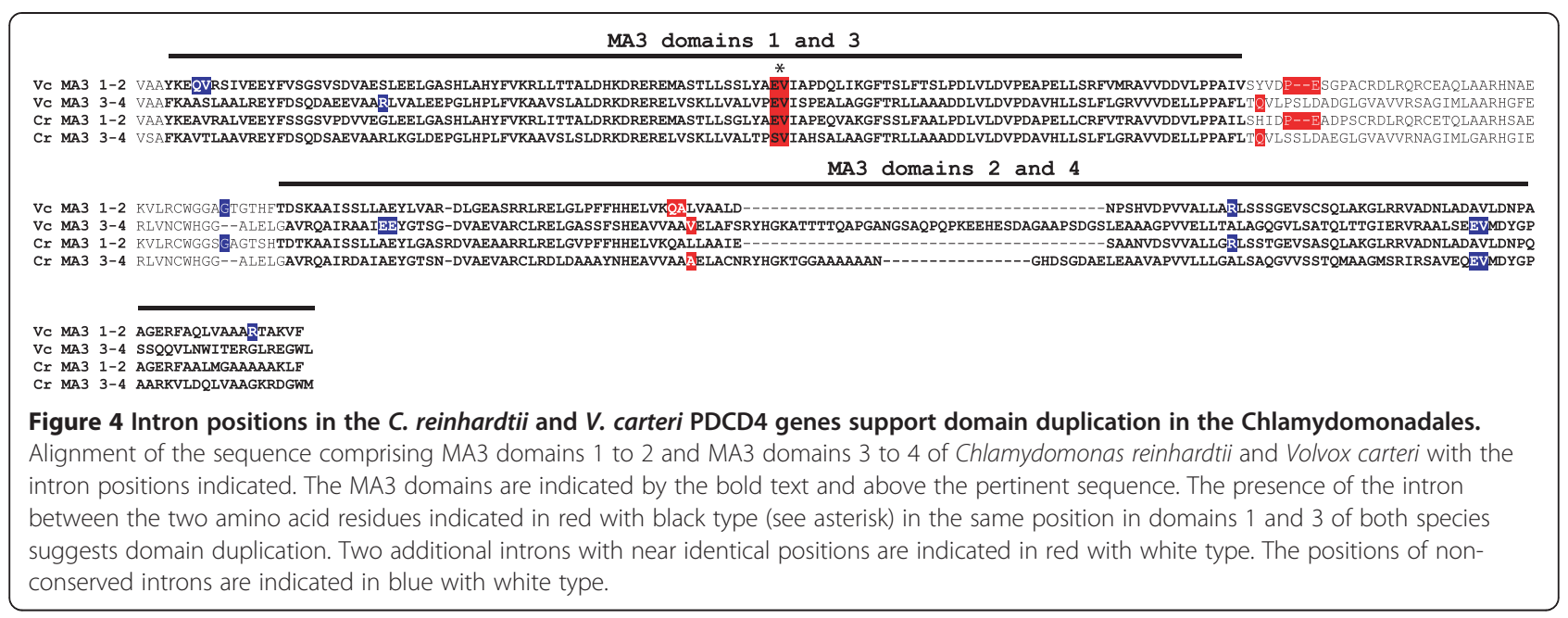

appearance of a four MA3 domain PDCD4 homolog in C. reinhardtii and V. carteri likely represents an independent event from the appearance of the four MA3 domain PDCD4 homolog in the land plant lineage. This is because charophytes and chlorophytes (which include C. reinhardtii and $V$. carteri) are thought to have derived from a common ancestor that likely contained a two MA3 domain PDCD4 form of the protein that was maintained in older algal lineages (e.g., those in Mamiellales) but underwent duplication during later chlorophyte evolution.

Thus, examination of charophyte PDCD4 homologs might more precisely determine when the four MA3 domain form of the protein appeared during the evolution of land plants. Although little genome sequence information is available for charophytes, a search of the EST database identified a partial PDCD4 cDNA from Chaetosphaeridium globosum, representing the Coleochaetophyceae. Although the $5^{\prime}$-end of the cDNA is truncated, the predicted protein contains MA3 domains 2-4 and, unlike PDCD4 present in C. reinhardtii and $V$. carteri, the C. globosum homolog shares similarity to the regions between the MA3 domains of land plant PDCD4 homologs, particularly between the second and third MA3 domains (Figure 5) which represents the fusion site during the putative duplication of the two MA3 domain form of PDCD4. This similarity between C. globosum PDCD4 and higher plants is in stark contrast to the lack of similarity of the region between the second and third MA3 domains of $C$. reinhardtii and $V$. carteri PDCD4 with higher plants, both in sequence and in length (Figure 5). Moreover, the fourth MA3 domain of the C. reinhardtii and $V$. carteri PDCD4 is interrupted by a sequence not present in C. globosum or higher plant PDCD4 homologs. Although this insertion likely occurred subsequent to the duplication event that gave rise to the four MA3 domain PDCD4 homolog in these chlorophytes, the PDCD4 of the Chlamydomonadales does not contain four uninterrupted MA3 domains as a consequence. These data suggest, therefore, that the appearance of a PDCD4 protein with four uninterrupted MA3 domains predated the colonization of land and occurred during charophyte evolution.

\section{The PDCD4 gene family underwent expansion during land plant evolution}

The PDCD4 homolog in C. reinhardtii and V. carteri is encoded by a single gene as it appears to be in other algae and algal relatives (Table 1). The PDCD4 gene family had expanded to two members by the appearance of early land plants such as P. patens and S. moellendorffii. Two members are also present in several dicotyledonous species such as Vitis vinifera, Populus trichocarpa, Ricinus communis, Medicago truncatula, Glycine max, and Theobroma cacao whereas three members are present in other dicots such as Solanum lycopersicum, Gossypium raimondii, Thellungiella halophila, and Brassica rapa (Table 1). Similarly, two members are present in some monocotyledonous species such as Hordeum vulgare and Zea mays while other monocots have three members such as Sorghum bicolor, Brachypodium distachyon, and Oryza sativa (Table 1). In contrast to T. halophila, and B. rapa, the PDCD4 gene families of $A$. thaliana, A. lyrata, and Capsella rubella are even larger with each containing four members. The variable size of the gene family among angiosperm species suggests that the expansion from the two gene members present in $P$. patens and $S$. moellendorffii occurred in a species-specific manner.

Gene divergence often follows gene duplication. To determine how the plant PDCD4 gene family members may have diverged during the evolution of land plants, phylogenetic analysis of the gene family was performed. Because of the poor sequence conservation of the $\mathrm{N}$ terminus, only the region containing the four MA3 domains was used for the analysis. Although the $C$. globosum sequence is not full-length, it was included to 


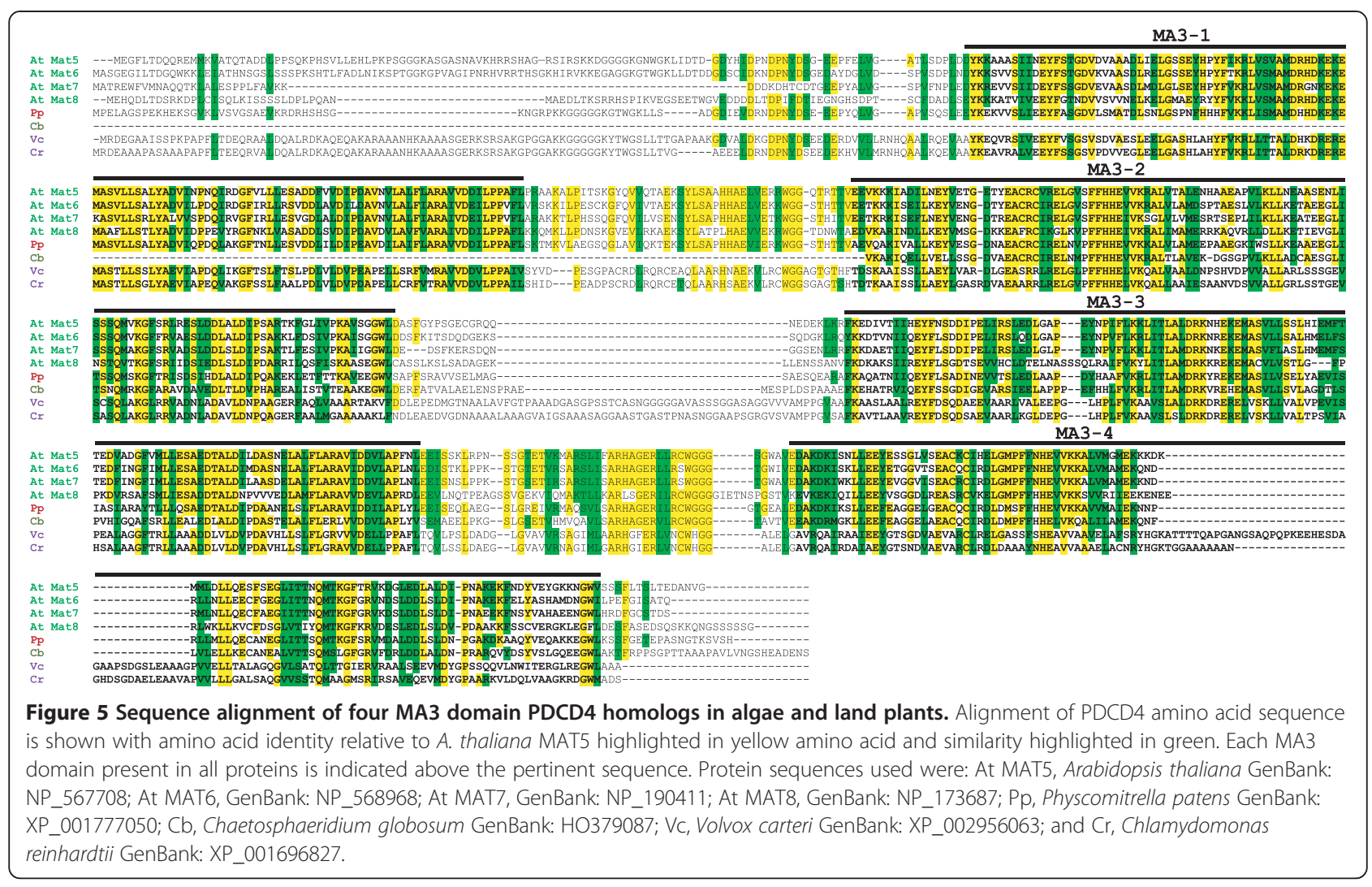

represent a progenitor sequence to land plants. Similarly, one of the P. abies PDCD4 homologs (MA_10693g0010) is not full-length but was included along with the second P. abies homolog (MA_2413g0010), which is full-length, to represent the two PDCD4 gene members of a more recent gymnosperm species.

The single PDCD4 gene family members of $C$. reinhardtii and $V$. carteri clustered together but not with the C. globosum sequence (Figure 6), which itself is more closely related to the PDCD4 homologs of land plants. This observation supports the notion that the four MA3 domain PDCD4 arose independently in chlorophytes and charophytes and that the PDCD4 homolog of land plants evolved from charophytes. The two PDCD4 homologs of $P$. patens clustered together but the two $S$. moellendorffii gene members exhibited some degree of divergence as they did not cluster together (Figure 6). In angiosperms, the PDCD4 gene family clusters into two distinct orthologous groups (Figure 6). One is represented by the $A$. thaliana MAT8 gene (the MAT8 subgroup) which is more closely related to MAT8-like gene members in other dicots such as C. rubella, $T$. halophila, B. rapa, G. raimondii, T. cacao, G. max, M. truncatula, $R$. communis, $P$. trichocarpa, $V$. vinifera, and $S$. lycopersicum, as well as in monocots such as $O$. sativa, S. bicolor, $Z$. mays, $H$. vulgare, $B$. distachyon than it is to the other three members of the $A$. thaliana
PDCD4 gene family (i.e., MAT5, MAT6, and MAT7), suggesting that genes in the MAT8 cluster are true orthologs. Regardless of the size of the MAT gene family, only one MAT8 gene is observed in those species in which a MAT8 homolog is present. In many species examined, the PDCD4 gene family is composed of just two members so that there is a single member in each subgroup. In some species, however, there are more than two PDCD4 genes and those that are not similar to MAT8 clustered together. An example is the A. thaliana gene family which, in addition to the single MAT8 gene, contains three additional members (i.e., the MAT5/6/7 subgroup), that are more closely related to one another than to any MAT8 homolog. As four members are present in C. rubella (Figure 6) and A. lyrata (data not shown), which cluster similarly to the $A$. thaliana gene family members, the MAT5/6/7 subgroup likely underwent gene expansion to three members from the two members of the MAT5/6/7 subgroup present in T. halophila, and B. rapa (Figure 6). The MAT5 and MAT6 subclades contain orthologs from $A$. lyrata (data not shown), C. rubella, T. halophila, and B. rapa (Figure 6) whereas the MAT7 subclade contains orthologs only from A. lyrata and C. rubella, data suggesting that MAT7 is likely the newest member of the MAT5/6/7 subgroup that appeared after the separation of Arabidopsis/ Capsella from Brassica. The two G. raimondii PDCD4 
Table 1 List of plant species and PDCD4 sequences used with the number of MA3 domains present in each protein

\begin{tabular}{|c|c|c|c|}
\hline Organism & Protein accession & Nucleotide accession & Number of MA3 domains \\
\hline \multirow[t]{4}{*}{ Arabidopsis thaliana } & NP_567708 & At4g24800 (MAT5) & 4 \\
\hline & NP_568968 & At5g63190 (MAT6) & 4 \\
\hline & NP_190411 & At3g48390 (MAT7) & 4 \\
\hline & NP_173687 & At1g22730 (MAT8) & 4 \\
\hline \multirow[t]{4}{*}{ Capsella rubella } & EOA15859 & & 4 \\
\hline & EOA14564 & & 4 \\
\hline & EOA23591 & & 4 \\
\hline & EOA39121 & & 4 \\
\hline \multirow[t]{3}{*}{ Thellungiella halophila } & Thhalv10024556m ${ }^{a}$ & & 4 \\
\hline & Thhalv10003735m ${ }^{\mathrm{a}}$ & & 4 \\
\hline & Thhalv10006903m ${ }^{a}$ & & 4 \\
\hline \multirow[t]{3}{*}{ Brassica rapa } & $\mathrm{Bra013836^{ \textrm {a } }}$ & & 4 \\
\hline & Bra038615 & & 4 \\
\hline & $\mathrm{Bra024534^{ \textrm {a } }}$ & & 4 \\
\hline \multirow[t]{3}{*}{ Gossypium raimondii } & Gorai.001G062000.1 ${ }^{\mathrm{a}}$ & & 4 \\
\hline & Gorai.003G108800.1 ${ }^{\mathrm{a}}$ & & 4 \\
\hline & Gorai.005G076400.1 ${ }^{\mathrm{a}}$ & & 4 \\
\hline \multirow[t]{2}{*}{ Theobroma cacao } & Thecc1EG014544t1 ${ }^{\mathrm{a}}$ & & 4 \\
\hline & Thecc1EG039086t1 ${ }^{a}$ & & 4 \\
\hline \multirow[t]{2}{*}{ Populus trichocarpa } & XP_002318100 & XM_002318064 & 4 \\
\hline & XP_002307530 & XM_002307494 & 4 \\
\hline \multirow[t]{2}{*}{ Ricinus communis } & XP_002511272 & XM_002511226 & 4 \\
\hline & XP_002527108 & XM_002527062 & 4 \\
\hline \multirow[t]{2}{*}{ Medicago truncatula } & XP_003608913 & XM_003608865 & 4 \\
\hline & XP_003619027 & XM_003618979 & 4 \\
\hline \multirow[t]{2}{*}{ Glycine max } & XP_003525619 & XM_003525571 & 4 \\
\hline & XP_003548962 & XM_003548914 & 4 \\
\hline \multirow[t]{2}{*}{ Vitis vinifera } & XP_002277813 & XM_002277777 & 4 \\
\hline & XP_002264439 & XM_002264403 & 4 \\
\hline \multirow[t]{3}{*}{ Solanum lycopersicum } & XP_004237843 & LOC101258853 & 4 \\
\hline & XP_004236308 & LOC101255979 & 4 \\
\hline & XP_004236309 & LOC101256273 & 4 \\
\hline \multirow[t]{2}{*}{ Eschscholzia californica } & TUHA-2426 ${ }^{\mathrm{b}}$ & & 4 \\
\hline & EVOD-8494 & & 4 \\
\hline \multirow[t]{2}{*}{ Aristolochia elegans } & PAWA5255 & & 4 \\
\hline & PAWA2930 & & 4 \\
\hline \multirow[t]{2}{*}{ Hordeum vulgare } & BAJ94459 & AK363255 & 4 \\
\hline & BAK08048 & AK376854 & 4 \\
\hline \multirow[t]{3}{*}{ Sorghum bicolor } & XP_002444968 & Sb07g002090 & 4 \\
\hline & XP_002448072 & Sb06g020520 & 4 \\
\hline & XP_002465627 & Sb01g042530 & 4 \\
\hline \multirow[t]{3}{*}{ Brachypodium distachyon } & XP_003573315 & XM_003573267 & 4 \\
\hline & XP_003579994 & XM_003579946 & 4 \\
\hline & XP_003561877 & XM_003561829 & 4 \\
\hline
\end{tabular}


Table 1 List of plant species and PDCD4 sequences used with the number of MA3 domains present in each protein (Continued)

\begin{tabular}{|c|c|c|c|}
\hline \multirow[t]{2}{*}{ Zea mays } & NP_001147914 & NM_001154442 & 4 \\
\hline & NP_001159302 & NM_001165830 & 4 \\
\hline \multirow[t]{3}{*}{ Oryza sativa } & NP_001060879 & Os08g0120500 & 4 \\
\hline & NP_001053119 & Os04g0482800 & 4 \\
\hline & AAN05329 & Os03g0222100 & 4 \\
\hline Illicium floridanum & VZCI-11530 & & 4 \\
\hline Amborella trichopoda & URDJ-37850 ${ }^{\mathrm{b}}$ & & 4 \\
\hline \multirow[t]{2}{*}{ Austrobaileya scandens } & FZJL-1758 b & & 4 \\
\hline & FZJL-1759 b & & 4 \\
\hline \multirow[t]{2}{*}{ Picea abies } & MA_2314g0010 & & 4 \\
\hline & MA_10693g0010 & & 4 \\
\hline Cycas micholitz & $X Z U Y-1711^{b}$ & & 4 \\
\hline Sundacarpus amarus & KLGF-13902 ${ }^{b}$ & & 4 \\
\hline \multirow[t]{2}{*}{ Selaginella moellendorffii } & XP_002967718 & XM_002964270 & 4 \\
\hline & XP_002979104 & XM_002979058 & 4 \\
\hline \multirow[t]{2}{*}{ Physcomitrella patens } & XP_001777050 & XM_001776998 & 4 \\
\hline & XP_001754785 & XM_001754733 & 4 \\
\hline Chaetosphaeridium globosum & HO379087 & & $4^{d}$ \\
\hline Volvox carteri & XP_002956063 & XM_002956017 & 4 \\
\hline Chlamydomonas reinhardtii & XP_001696827 & XM_001696775 & 4 \\
\hline Chlorella variabilis & EFN55681 & GL433844 & $4^{a}$ \\
\hline Ostreococcus tauri & XP_003079341 & XM_003079293 & 2 \\
\hline Ostreococcus lucimarimus & XP_001417999 & XM_001417962 & 2 \\
\hline Micromonas pusilla & XP_003056900 & XM_003056854 & 2 \\
\hline Micromonas sp. RCC299 & XP_002502542 & XM_002502496 & 2 \\
\hline Phaeodactylum tricornutum & XP_002184928 & XM_002184892 & 2 \\
\hline Ectocarpus siliculosus & CBJ33138 & FN648632 & 2 \\
\hline Thalassiosira pseudonan & XP_002295291 & XM_002295255 & 2 \\
\hline Aureococcus anophagefferens & EGB07675 & GL833130 & 2 \\
\hline Phytophthora sojae & EGZ06926 & $J H 159163$ & 2 \\
\hline Phytophthora infestans & XP_002899252 & XM_002899206 & 2 \\
\hline Albugo laibachii & CCA24083 & FR824266 & 2 \\
\hline
\end{tabular}

${ }^{\mathrm{a}}$ Obtained from Phytozome v9.1 [38].

bobtained from www.onekp.com.

'Obtained from the Spruce Genome Project [39].

dPartial sequence available suggests the likely presence of four MA3 domains.

homologs in the MAT5/6/7 subgroup exhibit considerable similarity (Figure 6), suggesting a relatively recent gene duplication event that produced these paralogs. A similar expansion of the PDCD4 gene family occurred in some monocot species such as $O$. sativa, S. bicolor, and $B$. distachyon, each of which contains two genes within the MAT5/6/7 subgroup (Figure 6). In these species, however, the two gene members in the MAT5/6/7 subgroup cluster into two distinct clades, suggesting that gene duplication occurred prior to speciation.
These data suggest that the two genes produced from the duplication of the original PDCD4 gene during early higher plant evolution might have been the progenitor genes for MAT8 and the MAT5/6/7 subgroups and the latter subgroup underwent expansion in some species. However, the considerable similarity of the two PDCD4 homologs in $P$. patens suggests that gene duplication occurred relatively recently in this species. In contrast, the two homologs in S. moellendorffii have diverged suggesting an earlier gene duplication event. The two 


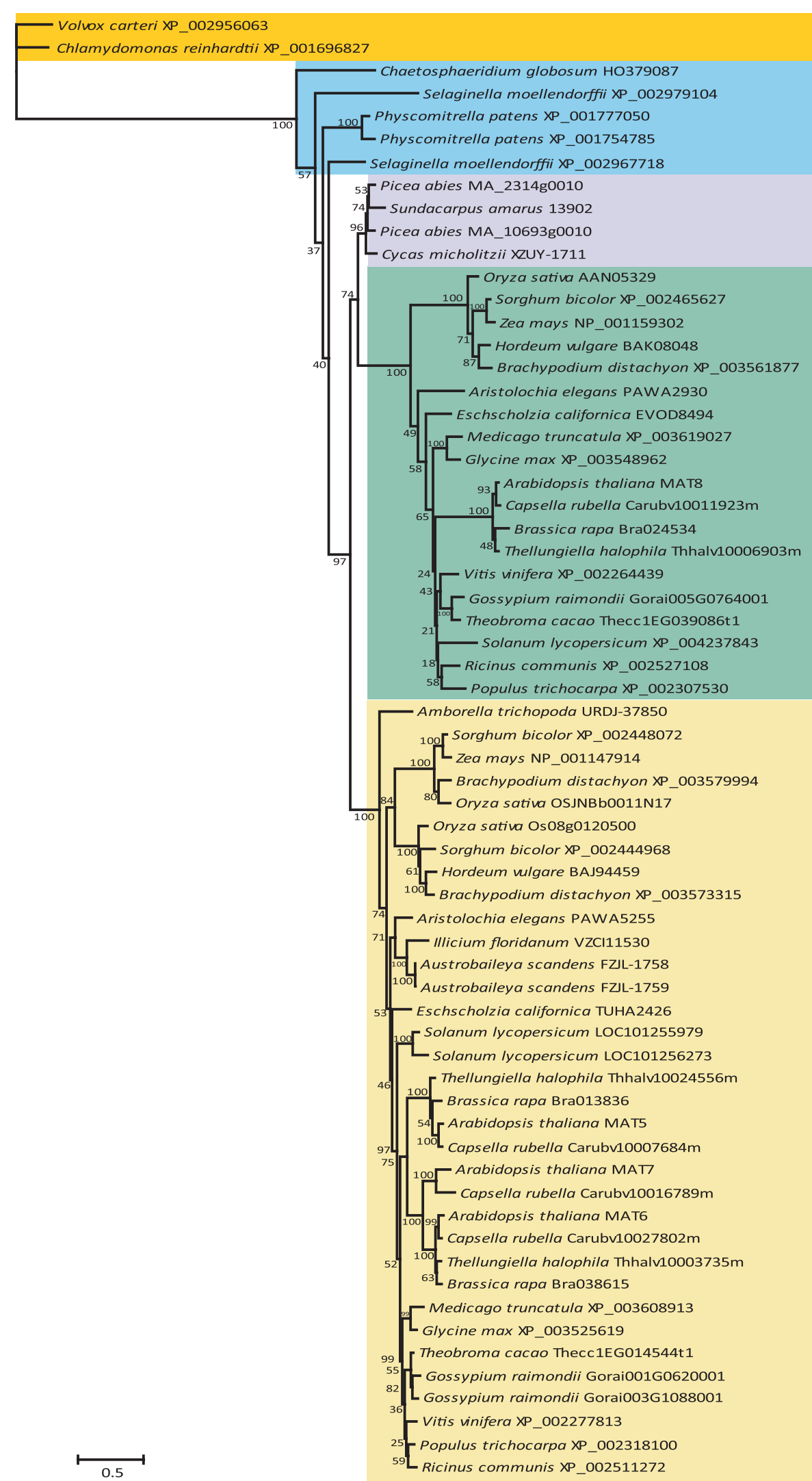

Figure 6 (See legend on next page.) 
gene members of $P$. patens and S. moellendorffii are sufficiently different from the MAT8 and MAT5/6/7 subgroups that it is not possible to assign them to either subgroup. Moreover, the gymnosperm PDCD4 homologs cluster in a subclade that is separate from the MAT8 and MAT5/6/7 subgroups, including the two homologs of $P$. abies, suggesting that the gymnosperm PDCD4 homologs have diverged from angiosperms homologs. No MAT8 homolog was identified in basal angiosperm species as the PDCD4 homologs in the basal angiosperms Amborella trichopoda, Austrobaileya scandens, and Illicium floridanum are more similar to the MAT5/ 6/7 subgroup than the MAT8 subgroup (Figure 6). A MAT8-like homolog was identified in Aristolochia elegans and Eschscholzia californica in addition to MAT5/6/7-like homologs (Figure 6). These observations suggest that MAT8 subgroup is not present in basal angiosperms but appeared at or prior to the evolution of species within the Piperales such as A. elegans.

The PDCD4 homologs in Cycas micholitz and Sundacarpus amarus contain deletions in each MA3 domain relative to the early land plants and angiosperms (Figure 7), perhaps suggesting a unique feature of gymnosperm PDCD4 homologs. However, examination of the $P$. abies and P. taeda PDCD4 homologs revealed that they are similar to more recently evolved angiosperm species in that the deletions present in C. micholitz and S. amarus are not present in the MA3 domains of $P$. abies (Figure 7) and $P$. taeda (data not shown). Moreover, examination of the PDCD4 homologs of the basal angiosperms $A$. trichopoda, A. scandens, and I. floridanum revealed that they too contain deletions in each MA3 domain that are identical to those observed in C. micholitz and S. amarus (Figure 7). However, the PDCD4 homologs of A. elegans and more recently evolved angiosperm species do not share these deletions (Figure 7).

To examine if the deletions in each MA3 domain affect the same region, the individual MA3 domains from $A$. thaliana MAT5 and the basal angiosperm $A$. trichopoda were aligned. Nearly the same two regions deleted in the first MA3 domain of A. trichopoda were also missing in the second MA3 domain (Figure 8). Similarly, nearly the same two regions deleted in the third MA3 domain of A. trichopoda were also missing in the fourth MA3 domain, although these were not conserved with the deleted regions in the first two MA3 domains (Figure 8). As the early evolved gymnosperm species share precisely the same deletions as the basal angiosperm species, the observations of $A$. trichopoda apply to these gymnosperm species as well.

As these deletions are not present in the early land plants $P$. patens and S. moellendorffii but appear in the early lineage of both gymnosperms and angiosperms only to disappear again during subsequent evolution of each lineage, the most parsimonious explanation is that the deletions in the MA3 domains of early evolved gymnosperm and angiosperm species likely occurred independently in the evolution of these species as they branched from the ancestral gymnosperm and angiosperm lineages. It is also formally possible that the deletions appeared subsequent to early land plant evolution but prior to the appearance of the distinct gymnosperm and angiosperm lineages only to disappear again during the subsequent evolution of each lineage although this possibility would seem less likely. Despite the deletions present in the basal angiosperm PDCD4 homologs, they are more similar to the MAT5/6/7 subgroup than the MAT8 subgroup (Figure 6), supporting the conclusion that the MAT8 member of the PDCD4 gene family evolved following basal angiosperm evolution and is specific to more recently evolved angiosperm species.

\section{Discussion and conclusions}

These results suggest that the domain organization of PDCD4 homologs in most lower plants, i.e., algae and algal relatives, is similar to those in animals in that it contains two MA3 domains but it underwent duplication to a four MA3 domain form in some recently evolved chlorophytes such as $C$. reinhardtii and $V$. carteri and, independently, in at least one charophyte such as C. globosum. That land plants did not evolve from chlorophytes, particularly from those species that contain a four MA3 domain PDCD4 homolog, supports the possibility of an independent duplication event during charophyte evolution. The sequence similarity between higher plant and C. globosum PDCD4 homologs at the fusion site between MA3 domain 2 and 3 and the significant sequence difference between higher plant and $C$. reinhardtii and $V$. carteri PDCD4 homologs in this same region further supports this conclusion. In addition 


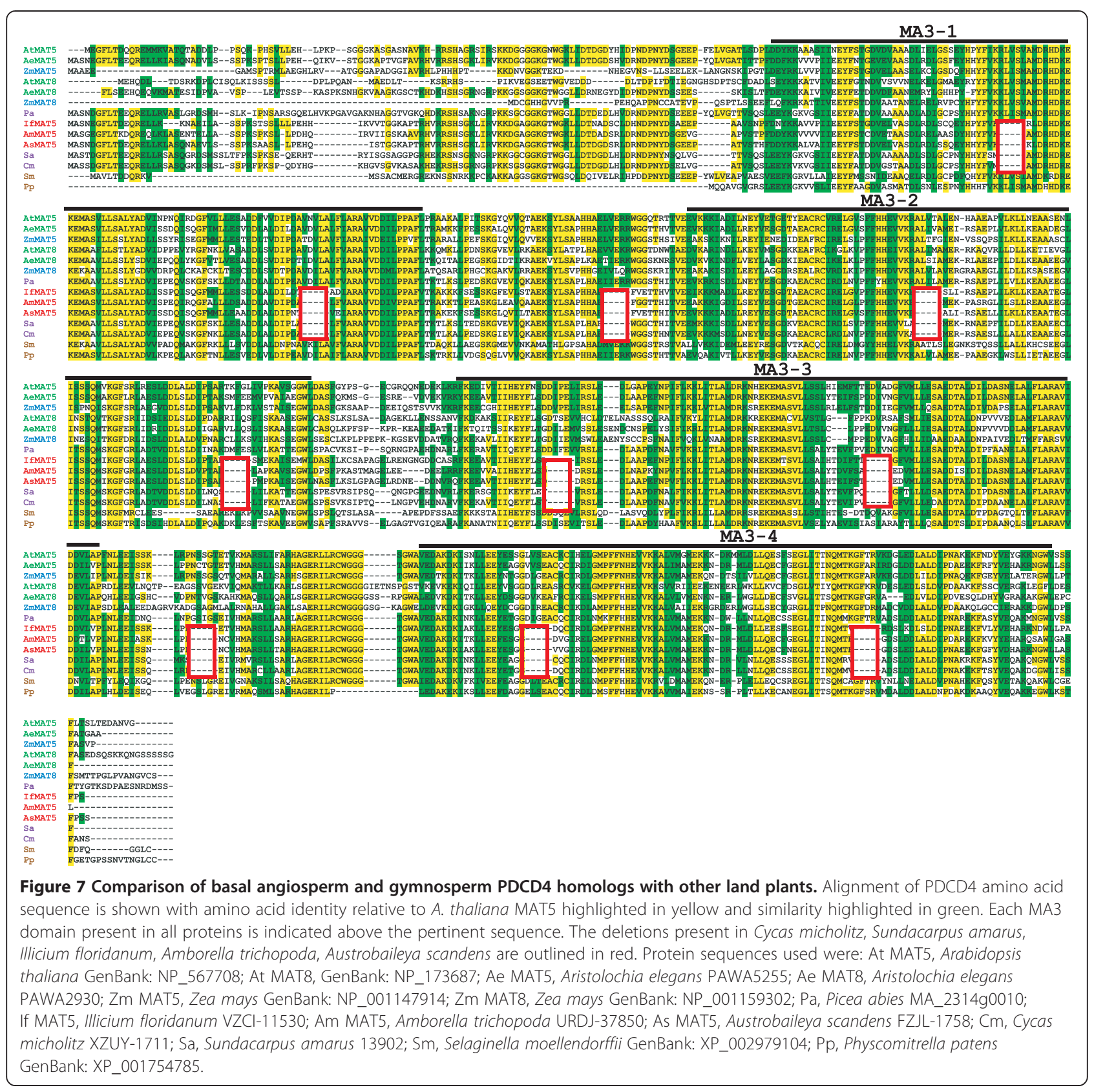

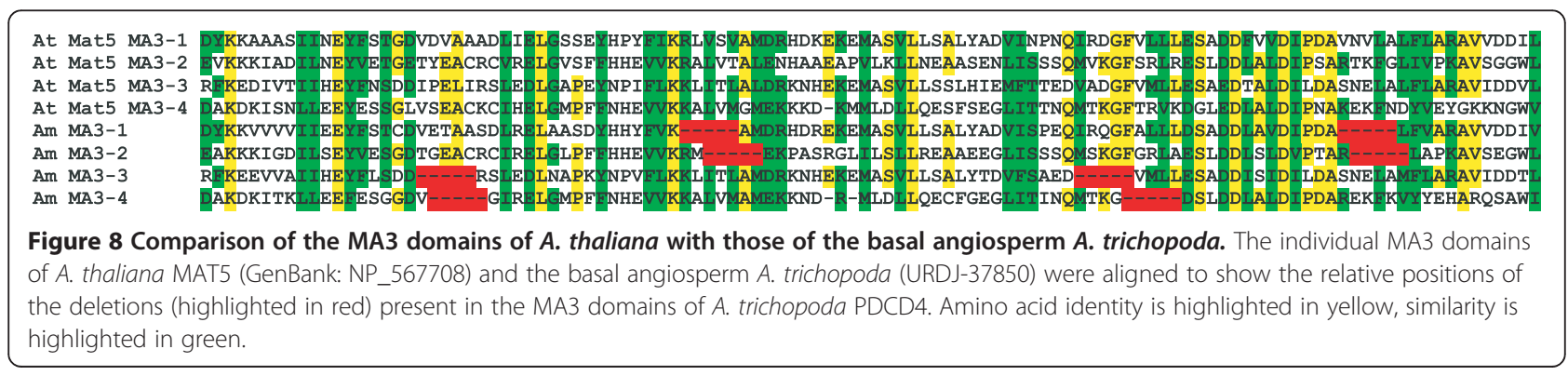


to the duplication of PDCD4 from a protein containing two MA3 domains to a protein containing four MA3 domains, the PDCD4 gene family expanded from a single member in algae to two or more members upon colonization of land and the evolution of higher plants. The expansion of the gene family occurred early during higher plant evolution as evidenced by the two member gene family present in bryophytes and lycophytes with additional expansion of the gene family in some higher plant species that appears to have occurred in a speciesspecific manner.

The PDCD4 homologs of the angiosperm species examined have diverged into MAT8-like and MAT5/6/ 7-like subgroups. No MAT8 homolog was identified in gymnosperm or basal angiosperm species, but appeared at or prior to the evolution of species within the Piperales such as A. elegans, suggesting that the MAT8 homolog is an angiosperm-specific member that evolved after the appearance of the most basal angiosperm species. Although no further expansion of the gene family appears to have occurred within the MAT8 subgroup as only one gene encoding a MAT8-like homolog was observed in those species whose PDCD4 gene family included a MAT8-like member, additional expansion did occur in the MAT5/6/7 subgroup in some dicot and monocot species in a species-specific manner resulting in the paralogs observed in this subgroup. For example, orthologs of A. thaliana MAT7 are found in A. lyrata and C. rubella but not in $T$. halophila and B. rapa, suggesting it appeared following the separation of Arabidopsis/Capsella from Brassica. Other recent gene duplication events may have occurred in $P$. patens and G. raimondii. In contrast, the expansion of the MAT5/6/ 7 subgroup in some monocots such as O. sativa, S. bicolor, and $B$. distachyon predated their speciation as each contains two genes within the MAT5/6/7 subgroup which cluster into two distinct clades. All PDCD4 homologs identified in basal angiosperm species were MAT5/6/7-like, supporting the conclusion that this form of PDCD4 evolved prior to the appearance of MAT8like homologs.

Interestingly, the PDCD4 homologs in early evolved gymnosperm and angiosperm species possess two deletions within each MA3 domain relative to early land plants. The observation that these deletions are present in both early evolved gymnosperm and angiosperm species supports the notion that they occurred prior to the appearance of the distinct gymnosperm and angiosperm lineages. However, the fact that these deletions are not observed in angiosperm species since (and including) the evolution of $A$. elegans and are not present in more recently evolved gymnosperm species such as $P$. abies and $P$. taeda, suggests that these deletions in the PDCD4 homologs of early evolved gymnosperm and angiosperm species likely occurred independently during the evolution of these species after they branched from the ancestral gymnosperm and angiosperm lineages. If they did occur independently in early gymnosperm and angiosperm species, it would suggest convergent evolution which may have been driven by the deletion of structural or functional elements within each MA3 domain that may have conferred an advantage to these species. The importance of the deleted regions within each MA3 domain is unknown but the elucidation of their structural or functional impact on the MA3 domains will provide insight into the adaption of PDCD4 proteins in early evolved gymnosperm and angiosperm species.

These observations collectively raise the question of what advantage does a four MA3 domain PDCD4 protein confer to recently evolved algal species and land plants and what advantage does expansion of the PDCD4 gene family confer to plants as they transitioned from an aquatic to a terrestrial environment? Loss of expression of just one of the four PDCD4 proteins in $A$. thaliana was sufficient to alter ethylene sensitivity and tolerance to salt [31]. The ability of MAT5 (ECIP1) to bind ethylene receptors and the EIN2 signaling component, suggests that plant PDCD4 may regulate ethylene signaling which in turn regulates responses to abiotic stresses such as salt [31]. Whether plant PDCD4 may interact also with eIF4A to inhibit protein synthesis as has been reported for animal PDCD4 remains to be determined. Moreover, its function in programmed cell death in plants has not been examined. An interesting correlation, however, is the presence in land plants and their closest algal relatives of a PDCD4 protein containing four uninterrupted MA3 domains with components involved in ethylene biosynthesis and signaling including homologs to the ETR2 and EIN4 ethylene receptors and the EIN2 downstream signaling component to which MAT5 binds $[31,34,35]$. This raises the intriguing possibility that the appearance of the four MA3 domain protein may represent the evolution of a protein involved in programmed cell death to one involved in abiotic stress-related hormone signaling similar to the evolution of ethylene receptors from twocomponent environmental sensor regulators [36]. The expansion of the PDCD4 gene family may have provided specificity of function if different PDCD4 isoforms are involved in different pathways or interact with different receptors within a single pathway such as in ethylene signaling. This would be particularly important following colonization of land which presents a more diverse array of stress conditions, such as desiccation, UV radiation, and temperature fluctuations, than would be present in many aquatic environments. Arabidopsis species contain five distinct ethylene receptors and MAT5 (ECIP1) interacts with just two of these, i.e., ETR2 and EIN4 (as well 
as EIN2). Whether other members of the PDCD4 gene family exhibit different specificities in their interactions with ethylene receptors, EIN2, or other proteins remains to be determined but the divergence of the MAT8 subgroup and the MAT5/6/7 subgroup might provide the basis for any functional specificity that exists within this family.

\section{Methods}

\section{Sequence alignment and phylogenetic analysis}

MA3-containing sequences obtained from Arabidopsis thaliana were used to query genome-wide analysis and comparative studies. MA3-containing sequences were obtained by BLAST searches of the NCBI [37] Phytozome v9.1 [38], and the Spruce Genome Project [39] protein, genome, and EST databases where appropriate. The Phytozome BLAST search implements NCBI Blast (v2.2.13). Reiterative searches of a particular species were performed using initial MA3-containing sequences from a species or from closely related species. Basal angiosperms and early evolved gymnosperm homologs were obtained from www.onekp.com. Predicted protein sequences from genomic and EST sequences were obtained using the ExPASy Translate tool [40]. Protein alignments were performed by Clustal Omega [41] with manual adjustments. Sequences queried included dicot and monocot plant genomes representing a diverse array of plants groups such as Arabidopsis relatives (Capsella rubella, Thellungiella halophila, and Brassica rapa), legumes (Glycine max and Medicago truncatula), the castor oil plant (Ricinus communis), cereals and grasses (Zea mays, Sorghum bicolor, Oryza sativa, Hordeum vulgare, and Brachypodium distachyon), fruits and vegetables (Vitis vinifera and Solanum lycopersicum), cotton (Gossypium raimondii), trees (Populus trichocarpa and Theobroma cacao), basal angiosperms (Amborella trichopoda, Austrobaileya scandens, and Illicium floridanum), gymnosperms (Cycas micholitz, Sundacarpus amarus, and Picea abies), bryophytes and lycophytes (Physcomitrella patens and Selaginella moellendorffii), green marine and fresh water algae (Chlamydomonas reinhardtii, Volvox carteri, Chlorella variabilis, Micromonas species, Ostreococcus species, and Chaetosphaeridium globosum), and stramenopiles or algal relatives (Ectocarpus siliculosus, Aureococcus anophagefferens, Phaeodactylum tricornutum, Thalassiisira pseudoonana, Phytophthora species, and Albugo laibachii). A list of protein sequences and cognate genes used for the comparative analysis is provided in Table 1. Maximum-likelihood phylogenetic trees were constructed using the PhyML software (v3.1) [42] with 1000 bootstrap replicates. The default LG amino acid replacement matrix [43] was used. Numbers included on each branch denote percentages of bootstrap support. Aligned sequences used for the phylogenetic analysis of Figure 2 are pres- ented in Additional file 4; for the phylogenetic analysis of Additional file 3 in Additional file 5; and for the phylogenetic analysis of Figure 6 in Additional file 6.

\section{Additional files}

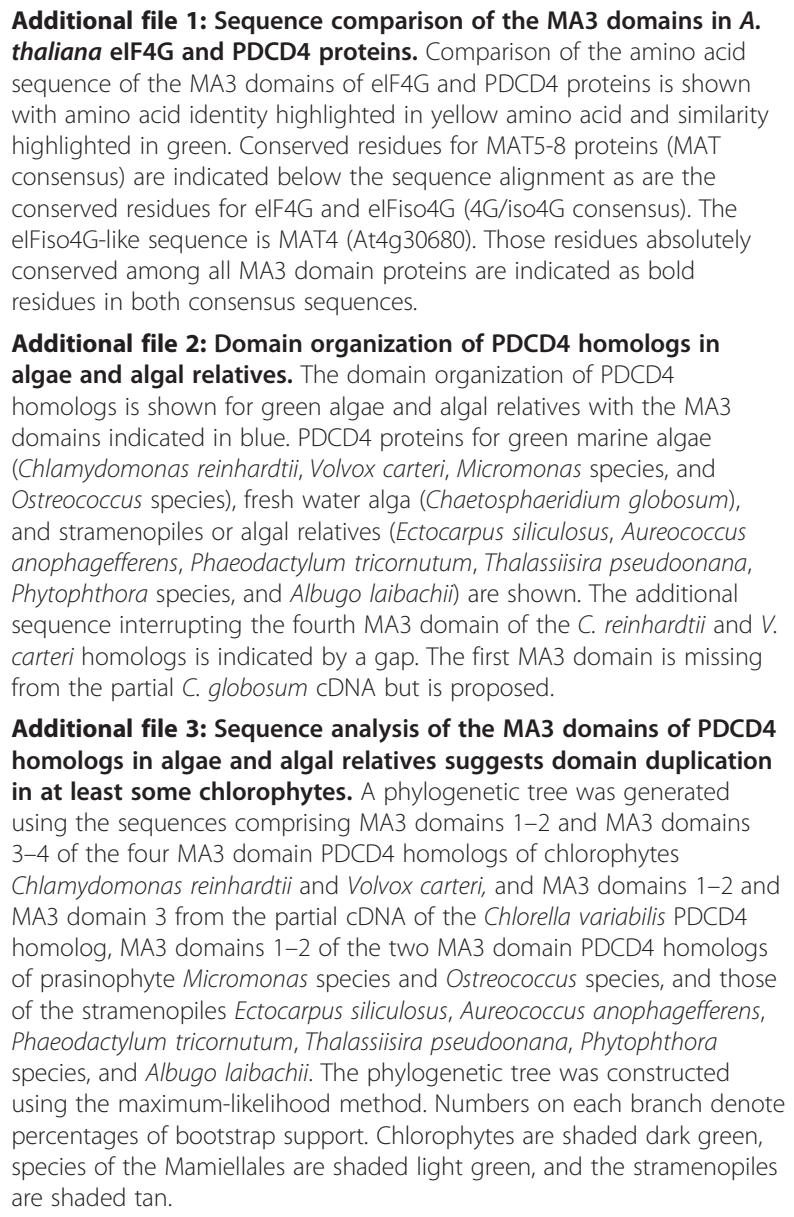

Additional file 2: Domain organization of PDCD4 homologs in algae and algal relatives. The domain organization of PDCD4

homologs is shown for green algae and algal relatives with the MA3 domains indicated in blue. PDCD4 proteins for green marine algae (Chlamydomonas reinhardtii, Volvox carteri, Micromonas species, and Ostreococcus species), fresh water alga (Chaetosphaeridium globosum), and stramenopiles or algal relatives (Ectocarpus siliculosus, Aureococcus anophagefferens, Phaeodactylum tricornutum, Thalassiisira pseudoonana, Phytophthora species, and Albugo laibachii) are shown. The additional sequence interrupting the fourth MA3 domain of the $C$. reinhardtii and $V$. carteri homologs is indicated by a gap. The first MA3 domain is missing from the partial C. globosum cDNA but is proposed.

Additional file 3: Sequence analysis of the MA3 domains of PDCD4 homologs in algae and algal relatives suggests domain duplication in at least some chlorophytes. A phylogenetic tree was generated using the sequences comprising MA3 domains 1-2 and MA3 domains 3-4 of the four MA3 domain PDCD4 homologs of chlorophytes

Chlamydomonas reinhardtii and Volvox carteri, and MA3 domains 1-2 and MA3 domain 3 from the partial CDNA of the Chlorella variabilis PDCD4 homolog, MA3 domains 1-2 of the two MA3 domain PDCD4 homologs of prasinophyte Micromonas species and Ostreococcus species, and those of the stramenopiles Ectocarpus siliculosus, Aureococcus anophagefferens, Phaeodactylum tricornutum, Thalassiisira pseudoonana, Phytophthora species, and Albugo laibachii. The phylogenetic tree was constructed using the maximum-likelihood method. Numbers on each branch denote percentages of bootstrap support. Chlorophytes are shaded dark green, species of the Mamiellales are shaded light green, and the stramenopiles are shaded tan.

Additional file 4: Aligned sequences used for the phylogenetic analysis of Figure 2.

Additional file 5: Aligned sequences used for the phylogenetic analysis of Additional file 3 .

Additional file 6: Aligned sequences used for the phylogenetic analysis of Figure 6.

\section{Abbreviations}

ECIP1: EIN2 C-terminal interacting protein 1; elF: Translation initiation factor; HEAT: Huntington, Elongation Factor 3, PR65/A, TOR; MAT: MA three; PABP: Poly(A) binding protein; PDCD4: Programmed cell death 4.

\section{Competing interest}

The authors declared that they have no competing interest.

\section{Authors' contributions}

DG conceived of the study and directed its design and coordination. DG, RL, and SC contributed to the sequence alignment, phylogenetic analysis, and preparation of the manuscript. All authors read and approved the final manuscript. 


\section{Acknowledgements}

The authors thank D. Soltis, J. Leebens-Mack, Tao Chen, T. Kutchan for sequences from the Onekp project. This work was funded by a grant from the National Science Foundation (DBI-0820047) and the University of California Agricultural Experiment Station.

\section{Author details}

'Department of Biochemistry, University of California, Riverside, CA 92521-0129, USA. ²Department of Botany and Plant Sciences, University of California, Riverside, CA 92521-0129, USA.

Received: 29 May 2013 Accepted: 13 September 2013

Published: 16 September 2013

\section{References}

1. Preiss T, Hentze M: Starting the protein synthesis machine: eukaryotic translation initiation. Bioessay 2003, 10:1201-1211.

2. Kapp LD, Lorsch JR: The molecular mechanics of eukaryotic translation. Annu Rev Biochem 2004, 73:657-704.

3. Pestova TV, Lorsch JR, Hellen CUT: The mechanism of translation initiation in eukaryotes. In Translational Control in Biology and Medicine. Edited by Mathews MB, Sonenberg N, Hershey JWB. Cold Spring Harbor Laboratory: Cold Spring Harbor Laboratory Press; 2007:87-128.

4. $\mathrm{Bi} X \mathrm{X}$, Ren $\mathrm{JH}$, Goss DJ: Wheat germ translation initiation factor elF4B affects elF4A and elFiso4F helicase activity by increasing the ATP binding affinity of elF4A. Biochem 2000, 39:5758-5765.

5. Rogers GW Jr, Richter NJ, Lima WF, Merrick WC: Modulation of the helicase activity of elF4A by elF4B, elF4H, and elF4F. J Biol Chem 2001, 276:30914-30922.

6. Cheng $S$, Gallie DR: Wheat eukaryotic initiation factor $4 B$ organizes assembly of RNA and elFiso4G, elF4A, and poly(A)-binding protein. $J$ Biol Chem 2006, 281:24351-24364.

7. Gallie DR: Protein-protein interactions required during translation. Plant Mol Biol 2002, 50:949-970.

8. Wei C-C, Balasta ML, Ren J, Goss DJ: Wheat germ poly(A) binding protein enhances the binding affinity of eukaryotic initiation factor $4 \mathrm{~F}$ and (iso) 4F for cap analogues. Biochem 1998, 37:1910-1916.

9. Cheng S, Gallie DR: Eukaryotic initiation factor $4 B$ and the poly(A)-binding protein bind elF4G competitively. Translation 2013, 1:e24038.

10. Tarun SZ, Sachs AB: A common function for mRNA 5' and 3' ends in translation initiation in yeast. Genes Develop 1995, 9:2997-3007.

11. Wells SE, Hillner PE, Vale RD, Sachs AB: Circularization of mRNA by eukaryotic translation initiation factors. Mol Cell 1998, 2:135-140.

12. Marcotrigiano J, Lomakin IB, Sonenberg N, Pestova TV, Hellen CU, Burley SK: A conserved HEAT domain within elF4G directs assembly of the translation initiation machinery. Mol Cell 2001, 7:193-203.

13. Bellsolell L, Cho-Park PF, Poulin F, Sonenberg N, Burley SK: Two structurally atypical HEAT domains in the C-terminal portion of human elF4G support binding to elF4A and Mnk1. Structure 2006, 14:913-923.

14. Morino S, Morino S, Imataka H, Svitkin W, Pestova TV, Sonenberg N: Eukaryotic translation initiation factor $4 \mathrm{E}$ (elF4E) binding site and the middle one-third of elF4GI constitute the core domain for capdependent translation, and the C-terminal one-third functions as a modulatory region. $\mathrm{Mol}$ Cell Biol 2000, 20:468-477.

15. Korneeva NL, First EA, Benoit CA, Rhoads RE: Interaction between the NH2terminal domain of elF4A and the central domain of elF4G modulates RNA-stimulated ATPase activity. J Biol Chem 2005, 280:1872-1881.

16. Korneeva NL, Lamphear BJ, Hennigan FL, Merrick WC, Rhoads RE: Characterization of the two elF4A-binding sites on human elF4G-1. J Biol Chem 2001, 276:2872-2879.

17. Pyronnet $\mathrm{S}$, Imataka $H$, Gingras AC, Fukunaga $R$, Hunter $T$, Sonenberg $N$ : Human eukaryotic translation initiation factor 4G (elF4G) recruits mnk1 to phosphorylate elF4E. EMBO J 1999, 18:270-279.

18. Browning KS: The plant translational apparatus. Plant Mol Biol 1996, 32:107-144

19. Cheng $S$, Gallie DR: Competitive and noncompetitive binding of elF4B elF4A, and the poly $(A)$ binding protein to wheat translation initiation factor elFiso4G. Biochem 2010, 49:8251-8265.

20. Suzuki C, Garces RG, Edmonds KA, Hiller S, Hyberts SG, Marintchev A Wagner G: PDCD4 inhibits translation initiation by binding to elF4A using both its MA3 domains. Proc Natl Acad Sci U S A 2008, 105:3274-3279.

21. Shibahara K, Asano M, Ishida Y, Aoki T, Koike T, Honjo T: Isolation of a novel mouse gene MA-3 that is induced upon programmed cell death. Gene 1995, 166:297-301.

22. Cmarik JL, Min H, Hegamyer G, Zhan S, Kulesz-Martin M, Yoshinaga H, Matsuhashi S, Colburn NH: Differentially expressed protein Pdcd4 inhibits tumor promoter-induced neoplastic transformation. Proc Natl Acad Sci U S A 1999, 96:14037-14042.

23. Yang HS, Jansen AP, Nair R, Shibahara K, Verma AK, Cmarik JL, Colburn NH: A novel transformation suppressor, Pdcd4, inhibits AP-1 transactivation but not NF-kB or ornithine decarboxylase transactivation. Oncogene 2001, 20:669-676.

24. Wang Q, Sun Z, Yang HS: Downregulation of tumor suppressor Pdcd4 promotes invasion and activates both beta-catenin/Tcf and AP-1 -dependent transcription in colon carcinoma cells. Oncogene 2008 27:1527-1535

25. Goke A, Goke R, Knolle A, Trusheim H, Schmidt H, Wilmen A, Carmody R, Goke $B$, Chen YH: DUG is a novel homologue of translation initiation factor 4G that binds elF4A. Biochem Biophys Res Commun 2002, 297:78-82.

26. Yang HS, Jansen AP, Komar AA, Zheng X, Merrick WC, Costes S, Lockett SJ, Sonenberg N, Colburn NH: The transformation suppressor Pdcd4 is a novel eukaryotic translation initiation factor $4 \mathrm{~A}$ binding protein that inhibits translation. Mol Cell Biol 2003, 23:26-37.

27. Yang HS, Cho MH, Zakowicz H, Hegamyer G, Sonenberg N, Colburn NH: A novel function of the MA-3 domains in transformation and translation suppressor Pdcd4 is essential for its binding to eukaryotic translation initiation factor 4A. Mol Cell Biol 2004, 24:3894-3906.

28. Loh PG, Yang HS, Walsh MA, Wang Q, Wang X, Cheng Z, Liu D, Song H: Structural basis for translational inhibition by the tumour suppressor Pdcd4. EMBO J 2009, 28:274-285

29. LaRonde-LeBlanc N, Santhanam AN, Baker AR, Wlodawer A, Colburn NH: Structural basis for inhibition of translation by the tumor suppressor Pdcd4. Mol Cell Biol 2007, 27:147-156.

30. Waters LC, Veverka V, Böhm M, Schmedt T, Choong PT, Muskett FW, Klempnauer KH, Carr MD: Structure of the C-terminal MA-3 domain of the tumour suppressor protein Pdcd4 and characterization of its interaction with elF4A. Oncogene 2007, 26:4941-4950.

31. Lei G, Shen M, Li ZG, Zhang B, Duan KX, Wang N, Cao YR, Zhang WK, Ma B, Ling HQ, Chen SY, Zhang JS: EIN2 regulates salt stress response and interacts with a MA3 domain-containing protein ECIP1 in Arabidopsis. Plant Cell Environ 2011, 34:1678-1692.

32. Gallie DR, Browning KS: elF4G functionally differs from elFiso4G in promoting internal initiation, cap-independent translation, and translation of structured mRNAs. J Biol Chem 2001, 276:36951-36960.

33. Lellis AD, Allen ML, Aertker AW, Tran JK, Hillis DM, Harbin CR, Caldwell C, Gallie DR, Browning KS: Deletion of the elFiso4G subunit of the Arabidopsis elFiso4F translation initiation complex impairs health and viability. Plant Mol Biol 2010, 74:249-263.

34. Wang W, Esch JJ, Shiu SH, Agula H, Binder BM, Chang C, Patterson SE, Bleecker $A B$ : Identification of important regions for ethylene binding and signaling in the transmembrane domain of the ETR1 ethylene receptor of Arabidopsis. Plant Cell 2006, 18:3429-3442

35. Timme RE, Delwiche CF: Uncovering the evolutionary origin of plant molecular processes: comparison of Coleochaete (Coleochaetales) and Spirogyra (Zygnematales) transcriptomes. BMC Plant Biol 2010, 10:96.

36. Bleecker $A B$ : Ethylene perception and signaling: an evolutionary perspective. Trends Plant Sci 1999, 4:269-274.

37. Altschul SF, Wootton JC, Zaslavsky E, Yu YK: The construction and use of log-odds substitution scores multiple sequence alignment. PLOS Comput Biol 2010, 6:e1000852.

38. Goodstein DM, Shu S, Howson R, Neupane R, Hayes RD, Fazo J, Mitros T, Dirks W, Hellsten U, Putnam N, Rokhsar DS: Phytozome: a comparative platform for green plant genomics. Nucl Acid Res 2012, 40:D1178-D1186.

39. Nystedt B, Street NR, Wetterbom A, Zuccolo A, Lin YC, Scofield DG, Vezzi F, Delhomme N, Giacomello S, Alexeyenko A, Vicedomini R, Sahlin K, Sherwood E, Elfstrand M, Gramzow L, Holmberg K, Hällman J, Keech O, Klasson L, Koriabine M, Kucukoglu M, Käller M, Luthman J, Lysholm F, Niittylä T, Olson A, Rilakovic N, Ritland C, Rosselló JA, Sena J, et al: The Norway spruce genome sequence and conifer genome evolution. Nature 2013, 497:579-584. 
40. Gasteiger E, Gattiker A, Hoogland C, Ivanyi I, Appel RD, Bairoch A: ExPASy: the proteomics server for in-depth protein knowledge and analysis. Nucl Acid Res 2003, 31:3784-3788.

41. Sievers F, Wilm A, Dineen D, Gibson TJ, Karplus K, Li W, Lopez R, McWilliam H, Remmert M, Söding J, Thompson JD, Higgins DG: Fast, scalable generation of high-quality protein multiple sequence alignments using Clustal Omega. Mol Syst Biol 2011, 7:539.

42. Guindon S, Dufayard JF, Lefort V, Anisimova M, Hordijk W, Gascuel O: New algorithms and methods to estimate maximum-likelihood phylogenies: assessing the performance of PhyML 3.0. Systematic Biol 2010, 59:307-321.

43. Le SQ, Gascuel O: LG: an improved, general amino-acid replacement matrix. Mol Biol Evol 2008, 25:1307-1320.

doi:10.1186/1471-2148-13-199

Cite this article as: Cheng et al: The unique evolution of the

programmed cell death 4 protein in plants. BMC Evolutionary Biology

2013 13:199.

\section{Submit your next manuscript to BioMed Central and take full advantage of:}

- Convenient online submission

- Thorough peer review

- No space constraints or color figure charges

- Immediate publication on acceptance

- Inclusion in PubMed, CAS, Scopus and Google Scholar

- Research which is freely available for redistribution 